\title{
Supporting breastfeeding during humanitarian emergencies
}

Natalie V Scime

Faculty Reviewer: Shauna M Burke, MA, PhD (School of Health Studies)

Infants (birth to one year of age) are among the most vulnerable population groups during humanitarian emergencies. ${ }^{1}$ In these situations, preventable diseases such as malnutrition, diarrheal diseases, and acute respiratory infections are some of the most common contributors to infant death and disease. ${ }^{2}$ As such, survival strategies targeting infant and child nutrition have been emphasized as emergency response priorities, with much of the discourse on this topic focusing on the merits of breastfeeding (typically in comparison to infant formula).

The World Health Organization recommends that all infants are exclusively breastfed (ie given only breast milk unless medically necessary) from birth until 6 months of age, followed by the introduction of complementary foods and continued breastfeeding for up to 2 years. ${ }^{3,4}$ Decades of research supports this recommendation, providing evidence for the far-reaching benefits of breastfeeding for both mothers and infants. ${ }^{5}$ Some breastfeeding-related benefits are especially vital during a humanitarian emergency. Breast milk is regarded as the optimal source of nourishment for infants, thus reducing the risk of malnutrition. ${ }^{6,7}$ Not only is breast milk nutritionally superior to formula in that it provides the appropriate balance of carbohydrates, fatty acids, protein, vitamins, and minerals in highly digestible forms, but breast milk also adapts its composition to meet the nutritional needs of growing infants. ${ }^{7}$ In addition, breastfeeding protects infants against infection-related morbidity ${ }^{8}$ and mortality ${ }^{9}$ due to the antimicrobial, anti-inflammatory, and antioxidant biomolecules found in breast milk. ${ }^{10}$ Mothers also receive benefits from breastfeeding including a reduced physiological response to stress. ${ }^{11}$ This may assist in dealing with the taxing circumstances of an emergency, as well as reduce stress-induced immunosuppression and its associated health sequelae..$^{12,13}$

Further, breastfeeding provides a sustainable infant feeding option in the face of poor sanitation, lack of clean water access, and poverty. ${ }^{14}$ In accounting for one week's worth of emergency supplies, an Australian study showed that it costs $\mathrm{A} \$ 50$ to provide necessary supplies for an exclusively breastfed infant, $\mathrm{A} \$ 250$ for an infant fed with powdered formula, and A $\$ 550$ for an infant fed with ready-to-use liquid formula. ${ }^{15}$ The authors also noted that while 2 items (diapers and wipes) are needed to support breastfed infants, 12 to 16 items (eg formula, detergent, feeding bottles) are required for formula-fed infants. The amount of time needed to safely and properly prepare formula can also be burdensome. Authors of a study conducted in a rural South African setting where electricity, gas, and tap water were inaccessible found that it took 21 to 25 minutes to prepare one formula feed, for a total of 2.5 hours of daily feeding preparation without accounting for time spent feeding the infant. ${ }^{16}$
Unfortunately, the health and sustainability advantages of breastfeeding seem to be overlooked during emergencies, with several emergency response reports detailing the uncontrolled distribution of donated formula. ${ }^{17}$ The detrimental consequences of such widespread formula distribution have been outlined in several epidemiological studies. ${ }^{18-20}$ In one study recounting the aftermath of an earthquake in Indonesia, the authors found strong and significant positive associations between both mothers receiving donated formula and changes in infant feeding practices (from breastfeeding to formula feeding), and between mothers receiving formula and the onset of infant diarrhea. ${ }^{18}$ In another study of 4 tsunami-affected villages in India, the authors found that the occurrence of diarrhea was 3 times higher among infants who consumed donated formula compared to those who did not. ${ }^{19}$ Furthermore, an evaluation of children affected by a flood in Africa showed that a significant risk factor for diarrhea was not breastfeeding (ie receiving breast milk substitutes such as formula or cow's milk), and that most of the deaths in children under 2 years of age were among those whose HIV-infected mothers received free formula. ${ }^{20}$

\section{UNFORTUNATELY, THE HEALTH AND SUSTAINABILITY ADVANTAGES OF BREASTFEEDING SEEM TO BE OVERLOOKED DURING EMERGENCIES, WITH SEVERAL EMERGENCY

$$
\begin{array}{r}
\text { RESPONSE REPORTS DETAILING THE } \\
\text { UNCONTROLLED DISTRIBUTION }
\end{array}
$$$$
\text { OF DONATED FORMULA. }
$$

In addition to health consequences, there are important ethical considerations regarding the supply of formula during humanitarian emergencies. The packaging of several formula products sold worldwide have been found to violate the International Code of Marketing of Breast-milk Substitutes. ${ }^{21-24}$ This code was adopted in 1981 by the World Health Assembly, in part to combat the exploitive and misleading marketing tactics utilized by the formula industry; such tactics include no label warning about the hazards of improper formula preparation, ambiguous claims about nutritional adequacy or similarity to breast milk, and photos idealizing the use of formula. ${ }^{25}$ In addition, the uncontrolled distribution of formula without offering breastfeeding support, assessing a mother's lactation circumstances, or providing accurate knowledge about the benefits and safety of breastfeeding undermines a woman's funda- 
mental right to breastfeed. ${ }^{26,27}$ Given that most emergencies take place in impoverished and developing countries with populations of low health literacy, ${ }^{28,29}$ the ethics of formula distribution cannot be ignored.

Much of the literature on breastfeeding during humanitarian emergencies recommends that mothers be provided with safe, private spaces to breastfeed and access to trained breastfeeding support.,17,30-32 In addition to health professionals, evidence points to peer counsellors as an effective strategy for supporting breastfeeding in developing and developed countries. ${ }^{33}$ Support may include practical (eg assistance with proper technique), informational (eg education about lactation physiology) and emotional (eg encouragement and patience) components. Connections with existing breastfeeding support organizations such as La Leche League, an international organization that promotes mother-to-mother breastfeeding support and information (http://www.llli.org/), can also serve as a valuable resource for emergency responders and mothers. Lastly, formula should remain available to mother-infant dyads that meet needs-based criteria, and should be distributed in plain packaging free of company advertising with the necessary sterile supplies (including clean water). ${ }^{22}$

As a growing number of researchers and international agencies focus on the impact of infant feeding practices during humanitarian emergencies, there appears to be a need for a more collaborative and informed response approach that supports and prioritizes breastfeeding. Although formula may be viewed as a convenient (and sometimes free by donation) solution to calm a hungry, crying infant and anxious mother, the negative ramifications noted above likely exceed the immediate gains. Taken together, the evidence demonstrates that breastfeeding is medically, economically, and ethically superior to infant formula feeding during humanitarian emergencies, as it represents the best option for protecting infant health and survival.

\section{REFERENCES}

1. O'Connor ME, Burkle FMJ, Olness K. Infant feeding practices in complex emergencies: a case study approach. Prehosp Disaster Med. 2001;16(4):231-238.

2. O'Dempsey TJD, Munslow B. Globalisation, complex humanitarian emergencies and health. Ann Trop Med Parasitol. 2006;100(5-6):501-515.

3. World Health Organization. Exclusive Breastfeeding [Internet]. [Cited October 27, 2016]. Available from: http://www.who.int/elena/titles/exclusive_breastfeeding/en/. Published 2016.

4. World Health Organization. Postnatal care of the mother and newborn 2013 [Internet]. Available from: http://apps.who.int/iris/bitstre am/10665/97603/1/9789241506649_eng.pdf. Published 2013.

5. Victora CG, Bahl R, Barros AJD, et al. Breastfeeding in the 21st century: epidemiology, mechanisms, and lifelong effect. Lancet. 2016;387(10017):475-490.

6. Eidelman A, Schanler R. Breastfeeding and the Use of Human Milk. J Am Acad Pediatr. 2012;129(3):e827-841

7. James DCS, Lessen R. Position of the American Dietetic Association: Promoting and supporting breastfeeding. J Am Diet Assoc. 2005;105(5):810-818.

8. Horta B., Victora C. Short-term effects of breastfeeding: a systematic review on the benefits of breastfeeding on diarrhoea and pneumonia mortality [Internet]. Available from: http://apps.who.int/iris/bitstre am/10665/95585/1/9789241506120_eng.pdf?ua=1. Published 2013.

9. Sankar MJ, Sinha B, Chowdhury R, et al. Optimal breastfeeding practices and infant and child mortality: a systematic review and meta-analysis. Acta Paediatr
Suppl. 2015;104(467):3-13.

10. Hassiotou F, Geddes DT. Immune Cell - Mediated Protection of the Mammary Gland and the Infant during Breastfeeding. Adv Nutr. 2015;(6):267-275

11. Mezzacappa ES. Breastfeeding and maternal stress response and health. Nutr Rev. 2004;62(7):261-268.

12. Jaedicke KM, Fuhrmann MD, Stefanski V. Lactation modifies stress-induced immune changes in laboratory rats. Brain Behav Immun. 2009;23(5):700-708.

13. Mezzacappa ES, Guethlein W, Vaz N, Bagiella E. A preliminary study of breast-feeding and maternal symptomatology. Ann Behav Med. 2000;22(1):71-79.

14. World Alliance for Breastfeeding Action. Breastfeeding: A Key to Sustainable Development [Internet]. Available from: http://worldbreastfeedingweek.org/ images/wbw2016-af-eng.jpg.

15. Gribble KD, Berry NJ. Emergency preparedness for those who care for infants in developed country contexts. Int Breastfeed J. 2011;6(1):16.

16. Papathakis PC, Rollins NC. Are WHO/UNAIDS/UNICEF-recommended replacement milks for infants of HIV-infected mothers appropriate in the South African context? Bull World Health Organ. 2004;82(3):164-171.

17. Gribble KD, Mcgrath M, Maclaine A, Lhotska L. Supporting breastfeeding in emergencies: Protecting women s reproductive rights and maternal and infant health. Disasters. 2011;35(4):720-738.

18. Hipgrave DB, Assefa F, Winoto A, Sukotjo S. Donated breast milk substitutes and incidence of diarrhoea among infants and young children after the May 2006 earthquake in Yogyakarta and Central Java. Public Health Nutr. 2012;15(2):307315.

19. Adhisivam B, Srinivasan S, Soudarssanane M, Deepak Amalnath S, Nirmal Kumar A. Feeding of Infants and Young Children in Tsunami Affected Villages in Pondicherry. Indian Pediatr. 2006;43:724-727.

20. Creek TL, Kim A, Lu L, et al. Hospitalization and mortality among primarily nonbreastfed children during a large outbreak of diarrhea and malnutrition in Botswana, 2006. J Acquir Immune Defic Syndr. 2010;53(1):14-19.

21. Parrilla-Rodríguez AM, Gorrín-Peralta JJ. Formula labeling violations to the WHO Code: a quantitative and qualitative analysis. P R Health Sci J. 2008;27(1):49-54.

22. Aguayo VM, Ross JS, Kanon S, Ouedraogo AN. Monitoring compliance with the International Code of Marketing of Breastmilk Substitutes in west Africa: multisite cross sectional survey in Togo and Burkina Faso. BMJ. 2003;326(7381):127.

23. Ergin A, Hatipoglu C, Bozkurt AI, et al. Compliance status of product labels to the international code on marketing of breast milk substitutes. Matern Child Health J. 2013;17(1):62-67.

24. Liu A, Dai Y, Xie X, Chen L. Implementation of International Code of Marketing Breast-Milk Substitutes in China. Breastfeed Med. 2014;9(9):467-472.

25. World Health Organization. International Code of Marketing of Breast-milk Substitutes [Internet]. Available from: http://www.who.int/nutrition/publications/ code_english.pdf. Published 1981.

26. Labbok M. Breastfeeding: A woman's reproductive right. Int J Gynecol Obstet. 2006;94(3):277-286.

27. Cattaneo A, Quintero-Romero S. Protection, promotion and support of breastfeeding in low-income countries. Semin Fetal Neonatal Med. 2006;11(1):48-53.

28. Dowse R. The limitations of current health literacy measures for use in developing countries The limitations of current health literacy measures for use in developing countries. J Commun Healthc. 2016;9(1):1-3.

29. Nutbeam D. The evolving concept of health literacy. Soc Sci Med. 2008;67(12):2072-2078.

30. Al Gasser NA, Dresden E, Keeney GB, Warren N. Status of women and infants in complex humanitarian emergencies. J Midwifery Women's Heal. 2004;49(4 SUPPL.):7-13.

31. Ayoya MA, Golden K, Ngnie-Teta I, et al. Protecting and improving breastfeeding practices during a major emergency: lessons learnt from the baby tents in Haiti. Bull World Health Organ. 2013;91(8):612-617.

32. Binns CW, Lee MK, Tang L, Yu C, Hokama T, Lee a. Ethical Issues in Infant Feeding After Disasters. Asia-Pacific J Public Heal. 2012;24(4):672-680.

33. Chapman DJ, Morel K, Anderson AK, Damio G, Pérez-Escamilla R. Breastfeeding peer counseling: from efficacy through scale-up. J Hum Lact. 2010;26(3):314326. 